\title{
Genetic variation in a closed line of the white shrimp Litopenaeus vannamei (Penaeidae)
}

\author{
Eloize Luvesuto, Patrícia Domingues de Freitas and Pedro Manoel Galetti Junior \\ Departamento de Genética e Evolução, Universidade Federal de São Carlos, São Carlos, SP, Brazil.
}

\begin{abstract}
The culture of the marine shrimp Litopenaeus vannamei has recently boosted the Brazilian shrimp industry. However, it is well known that selection methods based solely on phenotypic characteristics, a reduced number of breeders and the practice of inbreeding may promote a significant raise in the genetic similarity of the captive populations, leading to greater disease susceptibility and impairing both the growth and final size of the shrimps. We used four microsatellite loci to investigate genetic variation in three generations $\left(F_{5}, F_{6}\right.$ and $\left.F_{7}\right)$ of a closed and reared $L$. vannamei lineage. Although an accentuated heterozygosis deficit was detected, we also observed that the captive propagation of this lineage did not lead to a significant loss of genetic variability over the three generations studied. One possible reason for this is that the breeding conditions of this lineage were good enough to prevent any significant loss of genetic variability. However, three generations may have been insufficient to produce detectable changes in genetic frequencies in the loci studied. Alternatively, the microsatellite loci may have been non-neutral (biased) and related to the conditions in which the shrimps were kept, resulting in a similar allele pool in respect to these four microsatellites over the three generations studied. Any generalizations regarding microsatellite variation in closed shrimp lines may thus be incomplete and should be carefully analyzed.
\end{abstract}

Key words: broodstocks, inbreeding, penaeids, selection.

Received: August 24, 2006; Accepted: January 31, 2007.

\section{Introduction}

Culture of the Pacific white shrimp Litopenaeus vannamei has promoted the rapid growth and development of the Brazilian shrimp farm industry over the last few years, Brazil currently being the leading the shrimp aquaculture industry the Americas (ABCC, 2004). The shrimp L. vannamei is naturally distributed in the eastern Pacific from southern Mexico to northern Colombia and was introduced into Brazilian aquaculture during the early 1990's. However, in 1997 a Brazilian federal law restricted the importation of exotic aquatic species and all current $L$. vannamei broodstocks in Brazilian hatcheries have descended from the genetic material imported on several different occasions prior to 1997 (MAPA/SARC/DPA et al., 2001). The renewal of the Brazilian L. vannamei broodstock gene pool is still hindered by importation restrictions, which may result in cultures of this exotic species suffering severe genetic damage unless an efficient genetic monitoring program is implemented (Freitas and Galetti Jr., 2002, 2005). The loss of genetic variability in Brazilian L. vannamei

Send correspondence to Pedro Manoel Galetti Junior. Departamento de Genética e Evolução, Universidade Federal de São Carlos, Caixa Postal 676, 13565-905, São Carlos, SP, Brazil. E-mail: galettip@ufscar.br. broodstocks over succeeding generations and inbreeding depression in small populations may contribute to the reduction of the survival, growth and reproduction rates ( $\mathrm{Gje}$ drem, 2005) and the capacity of the broodstocks to adapt to environmental changes (Sbordoni et al., 1986).

A strict correlation between loss in genetic variation and shrimp production performance is well documented. In Litopenaeus stylirostris, low growth performance has been correlated with inbreeding in a closed line maintained in captivity for a long period of time (Bierne et al., 2000). The high incidence of dwarfed shrimp observed during the harvest of several species is believed to be a consequence of the reduced genetic diversity in culture stocks (Benzie et al., 1992, 1993) and, therefore, the efficiency of any selective breeding program is related to the level of genetic variability available in the population under selection (Goyard et al., 2003; Gjedrem, 2005).

Microsatellite analyses have been used to assess genetic variation in several penaeid species, such as $L$. vannamei (Wolfus et al., 1997), Marsupenaeus japonicus (Moore et al., 1999), L. stylirostris (Bierne et al., 2000), Penaeus monodon (Tassanakajon et al., 1998; Brooker et al., 2000; Pongsomboon et al., 2000, Xu et al., 2001), Litopenaeus schmitti (Maggioni et al., 2003; Borrel et al., 
2004) and Litopenaeus setiferus (Ball and Chapman, 2003) but, however, little is known on the genetics of the Brazilian L. vannamei broodstocks (Freitas and Galetti Jr 2002, 2005; De Francisco and Galetti Jr, 2005; Gonçalves et al., 2005). In the work described in the present paper we used microsatellite analysis to investigate the genetic variation in three consecutive generations $\left(\mathrm{F}_{5}, \mathrm{~F}_{6}\right.$ and $\left.\mathrm{F}_{7}\right)$ of a Brazilian closed breeder $L$. vannamei lineage.

\section{Material and Methods}

\section{Specimen selection}

The $L$. vannamei specimens used in the analyses were obtained from a closed breeder lineage owned by the Valença da Bahia Maricultura shrimp hatchery and farm located in the town of Valença in the northeastern Brazilian state of Bahia. These broodstocks descend from a pool of native founder animals imported mainly from Panama $(80 \%)$ and native and cultured L. vannamei from other countries such as Ecuador, Venezuela, Costa Rica and Mexico (20\%). After adaptation to the conditions in captivity, males and females were selected and the F1 generation was obtained following the first spawning. Each year, a new generation was obtained after the selection and mating of individual L. vannamei from the previous generation. The choice of the breeders used to initiate the subsequent generations involved three individual body size selection phases, an initial selection of about 35 thousand post-larval shrimps, followed by a second selection round of 8 thousand to 12 thousand young shrimps ( $\sim 80$ days old) and a third selection of 4,000 adults ( $\sim 240$ days old) that were also free of necrosis, displayed perfect antenna and rostrum and adequate pigmentation of gills, uropods and spermatophores. After the third selection, 140 couples were transferred to maturation tanks, with only egged females being kept in collective spawning tanks. In 1999 we started sampling these shrimp for genetic analysis, and in the subsequent years we obtained pleopod samples from a total of 85 shrimps from the $F_{5}, F_{6}$ and $F_{7}$ generations, these samples being collected and stored in $1 \mathrm{~mL}$ of $95 \%$ ethanol at $-20^{\circ} \mathrm{C}$. Genomic DNA extraction was performed according to Sambrook et al. (1989).

\section{Amplification of microsatellite loci}

Four primer sets, Pvan1758 and Pvan1815 (Cruz et al., 2002) along with Lvan1 and Lvan7 (Freitas et al., 2007), were used in a $25 \mu \mathrm{L}$ reaction volume containing 50-150 ng of DNA, $0.2 \mathrm{mM}$ of each dNTP, 7.5 pmoles $\mu \mathrm{L}^{-1}$ of each primer, 1.5-2.5 mM MgCl 2,1 unit of Taq DNA Polymerase and 1 to $1.25 \mathrm{x}$ PCR buffer. The Master Mix (2.5X) kit (Eppendorf) was used for the Lvan1 and Lvan7 loci. The primers were 2'-chloro-5'-fluoro-7', 8'-fused phenyl-1.4-dichloro-6-carboxyfluorescein (NED) fluorochrome-labeled for analysis in an automatic ABI Prism 377 DNA Sequencer (Applied Biosystems). Allele genotyping was performed using the GeneScan 2.1 and Genotyper 2.1 software (Applied Biosystems). The polymerase chain reaction (PCR) was performed in a PTC 100 thermocycler (MJ Research) for five minutes at $94^{\circ} \mathrm{C}$, followed by $35 \mathrm{cy}$ cles of $1 \mathrm{~min}$ at $94^{\circ} \mathrm{C}, 1 \mathrm{~min}$ at the optimum annealing temperature of each primer and $1 \mathrm{~min}$ at $72{ }^{\circ} \mathrm{C}$, with a final elongation for $20 \mathrm{~min}$ at $72{ }^{\circ} \mathrm{C}$.

\section{Statistical analyses}

The expected heterozygosity (Levene, 1949) and $F_{\text {IS }}$ (f) estimates (Weir and Cockerham, 1984) were calculated using the Genepop 3.4 software (Raymond and Rousset, 1995). The observed heterozygosis values in the analyzed generations were compared using the non-parametric Kruskal-Wallis test (Zar, 1999). The estimates of the exact $P$-values for the tests of conformity to the expectations of the Hardy-Weinberg equilibrium were calculated using the Markov-Monte Carlo chain randomization method (Guo and Thompson, 1992) and the values adjusted using the Bonferroni correction (Rice, 1989). The genotypic linkage disequilibrium was tested through the creation of contingency tables for all loci pairs in each population and posterior application of the Markov chain probability test. For all analyses, the chain parameters were as follows: dememorization number, 1000; number of batches 100; number of iterations per batch, 1000. The number of batches was sufficient for randomization, since it generated a low standard error, that is, less than 0.01 . The pairwise comparisons for all populations with all loci were performed and combined throughout all loci using Fisher's method for the results of combined tests. The $F_{\mathrm{ST}}$ values (Weir and Cockerham, 1984) and significance of the $F_{\mathrm{IS}}$ (f) values were estimated using the FSTAT 2.9.3.2 program (Goudet, 2002). The null hypothesis $\left(\mathrm{H}_{0}\right)$ of the identical distribution of the allelic and genotypic frequencies throughout the populations was tested by calculating an unbiased significance estimate of the probability test (Raymond and Rousset 1995).

\section{Results and Discussion}

A total of 65 alleles were observed in the three generations studied, 13 for Lvan1, 17 for Lvan7, 21 for Pvan1758 and 14 for Pvan1815. No genotypic disequilibrium was found for any of the loci analyzed. The frequency of the most common alleles ranged from 0.139 for alleles 166 , 174 and 184 in the Lvan7 locus to 0.35 for allele 135 in the Lvan1 locus. The Lvan1 135 allele was the only allele predominant in all three generations studied, but whether or not phenotype breeder selection is promoting its increased frequency is still an open question. In the three generations studied most loci showed a significant deviation from the Hardy-Weinberg equilibrium $(\mathrm{p}<0.012)$ when the Bonferroni correction (Rice, 1989) was applied and the $F_{\text {IS }}$ values obtained (Table 1) could be probably due to genetic drift, inbreeding and selection effects. Heterozygote deficit was 
Table 1 - Number of Litopenaeus vannamei analyzed (n), observed heterozygosity $\left(\mathrm{H}_{\mathrm{o}}\right)$, expected heterozygosity $\left(\mathrm{H}_{\mathrm{e}}\right)$, number of observed alleles per locus per generation $(\mathrm{NOA})$, frequency of the most common allele $\left(\mathrm{f}_{(\mathrm{MC})}\right)$, most common allele $(\mathrm{MCA})$, inbreeding coefficient $\left(F_{\mathrm{IS}}\right)$ and its significance (p) for the three Brazilian L. vannamei broodstocks.

\begin{tabular}{|c|c|c|c|c|c|c|c|c|}
\hline $\begin{array}{l}\text { Broodstock and } \\
\text { microsatellite loci }\end{array}$ & $\mathrm{n}$ & $\mathrm{H}_{\mathrm{o}}$ & $\mathrm{H}_{\mathrm{E}}$ & NOA & $\mathrm{f}_{(\mathrm{MC})}$ & MCA & $F_{\text {IS }}$ & $\mathrm{p}$ \\
\hline \multicolumn{9}{|l|}{ F5 broodstock } \\
\hline Lvan1 & 20 & 0.35 & 0.80 & 7 & 0.350 & 135 & 0.569 & 0.0003 \\
\hline Lvan7 & 18 & 0.39 & 0.92 & 12 & 0.139 & $166 / 174 / 184$ & 0.586 & 0.0001 \\
\hline Pvan 1758 & 20 & 0.40 & 0.88 & 10 & 0.250 & 189 & 0.550 & 0.0001 \\
\hline Pvan 1815 & 20 & 0.35 & 0.91 & 12 & 0.175 & 133 & 0.623 & 0.0001 \\
\hline Mean & & 0.37 & 0.88 & 10.3 & & & 0.583 & 0.0001 \\
\hline Deviation & & 0.03 & 0.056 & & & & & \\
\hline \multicolumn{9}{|l|}{ F6 broodstock } \\
\hline Lvan1 & 19 & 0.68 & 0.77 & 7 & 0.342 & 135 & 0.112 & 0.2636 \\
\hline Lvan7 & 17 & 0.53 & 0.92 & 13 & 0.206 & 166 & 0.431 & 0.0001 \\
\hline Pvan 1758 & 19 & 0.47 & 0.94 & 13 & 0.158 & 185 & 0.495 & 0.0001 \\
\hline Pvan 1815 & 19 & 0.74 & 0.92 & 13 & 0.184 & 140 & 0.200 & 0.0128 \\
\hline Mean & & 0.60 & 0.88 & 11.5 & & & 0.319 & 0.0001 \\
\hline Deviation & & 0.12 & 0.08 & & & & & \\
\hline \multicolumn{9}{|l|}{ F7 broodstock } \\
\hline Lvan1 & 20 & 0.45 & 0.84 & 9 & 0.300 & 135 & 0.470 & 0.0005 \\
\hline Lvan7 & 20 & 0.85 & 0.91 & 13 & 0.250 & 172 & 0.062 & 0.2833 \\
\hline Pvan 1758 & 19 & 0.74 & 0.92 & 15 & 0.210 & 195 & 0.204 & 0.0172 \\
\hline Pvan1815 & 20 & 0.30 & 0.93 & 12 & 0.150 & 132 & 0.682 & 0.0001 \\
\hline Mean & & 0.58 & 0.90 & 12.3 & & & 0.355 & 0.0001 \\
\hline Deviation & & 0.25 & 0.04 & & & & & \\
\hline
\end{tabular}

observed for all studied generations and could be related to null alleles, preferential mating and sampling errors (Cruz et al., 2003).

The mean observed heterozygosity $\left(\mathrm{H}_{\mathrm{o}}\right)$ values varied from 0.37 to 0.60 and were significantly different $(p=0.018)$ between the three generations but similar to the mean values reported for diverse cultured shrimp species (reviewed by Benzie, 2000). Although sampling effects and a large variance promoted by highly polymorphic markers should not be dismissed, these results could be explained by a raise in the frequency of rare alleles in older generations and the consequent contribution of these alleles to the formation of new genotypic classes. This is particularly significant for the locus Pvan1758, which showed 10 alleles in the $\mathrm{F}_{5}, 13$ in the $\mathrm{F}_{6}$ and 15 in the $\mathrm{F}_{7}$ generations. The allele frequency distribution between the populations indicated a high similarity between populations in terms of the Lvan1, Lvan7 and Pvan1815 loci. However, the Pvan1758 locus showed a significant allele frequency difference when the $\mathrm{F}_{5} \times \mathrm{F}_{7}$ and $\mathrm{F}_{6} \times \mathrm{F}_{7}$ pairs were considered (Table 2). In addition, the diverse origin of the shrimps used during foundation of this closed lineage studied and the practices for the selection of breeders for the establishment of the subsequent generation could also favor an increase of heterozygotes if hybrid vigor is present.

The genotypic distribution analysis also detected no differentiation between the populations in relation to genotype frequency (Table 2), while a low $F_{\mathrm{ST}}$ value $\left(F_{\mathrm{ST}}=-0.004\right)$ indicated high homogeneity between the generations. However, it is well known that phenotypic selection, the employment of a reduced number of breeders for the establishment of subsequent generations and inbreeding all contribute to promoting a significant raise in the genetic similarity of captive populations (Freitas and Galetti Jr, 2005; Gjedrem, 2005). The small size of the broodstocks facilitates genetic drift and the consequent fixation of alleles, thus reducing diversity and allowing greater disease susceptibility, decreased growth and a smaller shrimp at harvest (Benzie, 2000; Bierne et al., 2000). Despite contributing to the maintenance of phenotypic characteristics of commercial interest, increased inbreeding rates may result in genetic homogenization and a drastic reduction in heterozygosis (Goyard et al., 2003; Freitas and Galetti Jr, 2005), although no such effects were detected in our study.

There are at least three possible explanations for our results. Firstly, it is possible that the captive breeding of this 
Table 2 - Probability of the differentiation test in the distribution of the gene ( $\mathrm{Ge}$ ) and genotypic $(\mathrm{Go})$ frequencies between Litopenaeus vannamei generations $\mathrm{F}_{5}, \mathrm{~F}_{6}$ and $\mathrm{F}_{7}$. Values of $\mathrm{p}<0.05$ reject the null hypothesis $\left(\mathrm{H}_{0}\right)$ that the allele distribution is identical throughout the generations.

\begin{tabular}{|c|c|c|c|c|c|c|c|c|c|c|}
\hline \multirow{3}{*}{ Broodstocks } & \multicolumn{10}{|c|}{ Microsatellite loci } \\
\hline & \multicolumn{2}{|c|}{ Lvan1 } & \multicolumn{2}{|c|}{ Lvan7 } & \multicolumn{2}{|c|}{ Pvan 1758} & \multicolumn{2}{|c|}{ Pvan1815 } & \multicolumn{2}{|c|}{ All loci } \\
\hline & $G e$ & Go & Ge & Go & Ge & Go & Ge & Go & Ge & Go \\
\hline F5 x F6 & 0.227 & 0.467 & 0.173 & 0.598 & 0.221 & 0.253 & 0.263 & 0.626 & 0.020 & 0.620 \\
\hline F5 x F7 & 0.111 & 0.382 & 0.175 & 0.442 & 0.005 & 0.064 & 0.095 & 0.572 & 0.000 & 0.253 \\
\hline F6 x F7 & 0.196 & 0.334 & 0.636 & 0.858 & 0.003 & 0.044 & 0.592 & 0.868 & 0.014 & 0.339 \\
\hline
\end{tabular}

closed L. vannamei lineage has indeed not yet resulted in a significant loss of genetic variability among the three generations studied. Secondly, three generations may not have been sufficient to detect genetic variation in the loci studied. Thirdly, the microsatellite loci studied were not neutral but all retained a certain degree of relationship with the conditions under which the broodstocks were reared, thus retaining a similar allele pool with respect to these alleles over the three generations studied. It thus seems that any generalization regarding microsatellite variation in a $L$. vannamei closed broodstock lines could be incomplete and should thus be carefully analyzed.

\section{Acknowledgments}

The authors thank Maricultura Valença Bahia hatchery for supplying the shrimps studied. This work was supported by the Brazilian agencies Conselho Nacional de Desenvolvimento Científico e Tecnológico (CNPq), Fundação de Amparo à Pesquisa do Estado de São Paulo (Fapesp) and Associação Brasileira de Criadores de Camarão (ABCC).

\section{References}

ABCC (2004) A carcinocultura brasileira. Revista da ABCC 1:30-45.

Ball AO and Chapman RW (2003) Population genetic analysis of white shrimp, Litopenaeus setiferus, using microsatellite genetic markers. Mol Ecol 12:2319-2330.

Benzie JAH, Frusher S and Ballment E (1992) Geographical variation in allozyme frequencies of Penaeus monodon (Crustacea, Decapoda) populations in Australia. Aust J Mar Freshwater Res 43:715-725.

Benzie JAH, Ballment E and Frusher S (1993) Genetic structure of Penaeus monodon in Australia: Preliminary data from allozymes and mtDNA. Aquaculture 111:89-93.

Benzie JAH (2000) Population genetic structure in penaeid prawns. Aquacult Res 31:95-119.

Bierne N, Beuzart I, Vonau V, Bonhomme F and Bedier E (2000) Microsatellite-associated heterosis in hatchery-propagated stocks of the shrimp Penaeus stylirostris. Aquaculture 184:203-219.

Borrel Y, Espinosa G, Romo J, Blanco G, Vázquez E and Sánchez JA (2004) DNA microsatellite variability and genetic differentiation among natural populations of the Cuban white shrimp Litopenaeus schmitti. Mar Biol 144:327-333.
Brooker AL, Benzie JAH, Blair D and Versini JJ (2000) Population structure of the giant tiger prawn Penaeus monodon in Australian waters, determined using microsatellite markers. Mar Biol 136:149-157.

Cruz P, Mejia-Ruiz H, Perez-Henriquez R and Ibarra AM (2002) Isolation and characterization of microsatellites in Pacific white shrimp Penaeus (Litopeanaeus) vannamei. Mol Ecol Notes 2:239-241.

Cruz P, Ibarra AM, Meija-Ruiz H, Gaffney PM and Perez-Henriquez R (2003) Genetic variability assessed by microsatellites in a breeding program of Pacific White Shrimp (Litopenaeus vannamei). Mar Biotechnol 6:157-164.

De Francisco AK and Galetti Jr PM (2005) Genetic distance between broodstocks of the marine shrimp Litopenaeus vannamei (Decapoda, Penaeidae) by mtDNA analyses. Genet Mol Biol 28:258-261.

Freitas PD and Galetti Jr PM (2002) PCR-based VNTR core sequence analysis inferring genetic diversity in shrimp Litopenaeus vannamei. Genet Mol Biol 25:431-434.

Freitas PD and Galetti Jr PM (2005) Assessment of the genetic diversity in five generations of a commercial broodstock line of Litopenaeus vannamei shrimp. Afr J Biotechnol 4:13621367.

Freitas PD, Jesus CM and Galetti Jr PM (2007) Isolation and characterization of new microsatellite loci in the Pacific white shrimp Litopenaeus vannamei and cross-species amplification in other penaeid species. Mol Ecol Notes 7:324-326.

Gjedrem T (2005) Selection and Breeding Programs in Aquaculture. Springer, Dordrecht, 364 pp.

Gonçalves MM, Lemos MVF, Galetti Jr PM, Freitas PD and Neto MAAF (2005) Fluorescent amplified fragment length polymorphism (fAFLP) analyses and genetic diversity in Litopenaeus vannamei (Penaeidae). Genet Mol Biol 28:267-270.

Goudet J (2002) FSTAT version 2.9.3.2, updated from Goudet (1995) FSTAT: A computer program to calculate $F$-statistics. J Heredity 86:485-486.

Goyard E, Arnaud S, Vonau V, Bishoff V, Mouchel O, Pham D, Wyban J, Boudry P and Aquacop (2003) Residual genetic variability in domesticated populations of the Pacific blue shrimp (Litopenaeus stylirostris) of New Caledonia, French Polynesia and Hawaii and some management recommendations. Aquat Living Resour 16:501-508.

Guo SW and Thompson EA (1992) Performing the exact test of Hardy-Weinberg proportions for multiple alleles. Biometrics 48:361-372.

Levene H (1949) On a matching problem arising in genetics. Ann Math Stat 20:91-94. 
Maggioni R, Rogers AD and Maclean N (2003) Population structure of Litopenaeus schmitti (Decapoda, Penaeidae) from the Brazilian coast identified using six polymorphic microsatellite loci. Mol Ecol 12:3213-3217.

MAPA/SARC/DPA, CNPq and ABCC (2001) Plataforma Tecnológica do Camarão Marinho Cultivado. Ministério da Agricultura, Pecuária e Abastecimento, Brasília, 267 pp.

Moore SS, Whan V, Davis GP, Byrne K, Hetzel DJS and Preston N (1999) The development and application of genetic markers for the Kuruma prawn Penaeus japonicus. Aquaculture 173:19-32.

Pongsomboon S, Whan V, Moore SS and Tassanakajon A (2000) Characterization of tri- and tetranucleotide microsatellites in the black tiger prawn Penaeus monodon. Sci Asia 26:1-8.

Raymond M and Rousset F (1995) An exact test for population differentiation. Evolution 49:1280-1283.

Rice WR (1989) Analyzing tables of statistical tests. Evolution 43:223-225.
Sambrook J, Fritish EF and Maniatis T (1989) Molecular Cloning: A Laboratory Manual. 2nd ed. Cold Spring Harbor Laboratory Press, Cold Spring Harbor.

Sbordoni VE, De Matthaeis E, Cobolli SM, La Rosa G and Mattoccia M (1986) Bottleneck effects and the depression of genetic variability in hatchery stocks of Penaeus japonicus (Crustacea, Decapoda). Aquaculture 57:239-251.

Tassanakajon A, Tiptawonnukul A and Rimphanitchayakit V (1998) Isolation and characterization of microsatellite markers in the black tiger prawn Penaeus monodon. Mol Mar Biol Biotechnol 7:55-61.

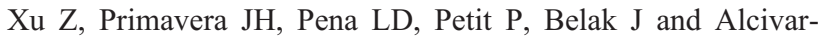
Warren A (2001) Genetic diversity of wild and cultured Black Tiger Shrimp (Penaeus monodon) in the Philippines using microsatellites. Aquaculture 199:13-40.

Zar JH (1999) Biostatistical Analysis. 4th ed. New Jersey, Prentice Hall, 663 pp.

Weir BS and Cockerham CC (1984) Estimating $F$-statistics for the analysis of population structure. Evolution 38:1358-1370.

Wolfus GM, Garcia DK and Mickinell S (1997) Application of the microsatellite technique for analysing genetic diversity in shrimp breeding programs. Aquaculture 152:36-47.

Associate Editor: Louis Bernard Klaczko 